\title{
La evaluación en narrativas orales de experiencia personal: esbozo clasificatorio
}

\author{
The evaluation within oral narratives of personal experience: \\ qualifying outline \\ Silvana Guerrero González \\ Universidad de Chile
}

RESUMEN. La 'evaluación' en la narración ha sido abordada en múltiples trabajos, desde los estudios iniciales de Labov \& Waletzky (1967) y Labov (1972). En la actualidad, las investigaciones que se hacen cargo de ella la estudian para determinar su variación social y/o para dar cuenta de sus funciones pragmáticas en la narrativa oral de experiencia personal. Esta nota no solo presenta una revisión crítica del tratamiento que ha recibido la 'evaluación' narrativa en lingüística, sino que propone también un esbozo clasificatorio para su estudio incluyendo en la propuesta la comunicación no verbal.

Palabras clave: recursos evaluativos, narración de experiencia personal, comunicación no verbal.

\begin{abstract}
The concept of 'evaluation' in narrative has been addressed in multiple studies since the seminal work by Labov \& Waletzky (1967) and Labov (1972). Presently, the studies that explore evaluation, try to determine social variation and/or to account for pragmatic functions in oral narratives of personal experience. This note is not only a critical review of the treatment that the concept of narrative 'evaluation' has received in linguistics, but it also proposes an outline of a classification for its study, which includes non-verbal communication.
\end{abstract}

Keywords: evaluative resources, personal experience narratives, non-verbal communication.

Data de recepción: 28-05-2019 - Data de aceptación: 15-10-2019. 


\section{OBJETIVOS Y ANTECEDENTES}

En esta nota se ofrece, en primer término, una reflexión acerca del tratamiento que ha recibido la 'evaluación' narrativa (Labov 1972, 2013), desde sus orígenes hasta la actualidad, a partir de la revisión de diversos trabajos. Se incluye luego un esbozo clasificatorio de recursos lingüísticos que permiten evaluar en el relato; se citan a este respecto trabajos propios y de otros autores, cuyo enfoque ha sido sociolingüístico y/o pragmalingüístico. Por último, se aborda el rol que adquiere la comunicación no verbal para el estudio de la 'evaluación' en el marco de la narrativa oral de experiencia personal.

Labov (2013) sostiene que la evaluación marca la parte central e informativa del relato, no obstante, podría aparecer cada vez que el hablante lo considere necesario. El autor señala que la evaluación otorga la posibilidad de identificar el foco temático de la narrativa y su importancia es que permite contrastar los eventos que realmente sucedieron con aquellos que pudieron haber ocurrido pero no necesariamente sucedieron. En un sentido más extremo y solo a modo de ejemplo, Silva-Corvalán \& Enrique-Arias (2017) destacan que la falta de expresividad en la narrativa oral, expresada en términos de ausencia de rasgos tales como habla reportada, repeticiones, exclamaciones, sonidos expresivos y gestos, sería equivalente a la falta casi total de evaluación. Se trata de una mirada más extrema, porque difícilmente existiría un relato de estas características. De manera consecuente, esta nota se centra en la evaluación del relato de experiencia personal ${ }^{1}$, puesto que, si bien ha recibido bastante atención en investigaciones en habla inglesa y española, los estudios no se han detenido en indagar acerca de la relevancia que adquiere la comunicación no verbal para evaluar la historia. Se contribuye así al estudio de la dimensión pragmático-discursiva con foco en la interacción cotidiana y a las narraciones que se generan en este marco.

Un aspecto que debe tenerse en cuenta para la lectura de esta nota es que las revisiones y reflexiones que aquí se presentan constituyen, en su mayoría, el resultado del trabajo empírico basado en narrativas orales de experiencia personal en español chileno, por lo tanto, los ejemplos que se emplean para ilustrar la clasificación son, en general, de esta variedad.

Narración, relato e historia se emplean de manera indistinta. Guerrero (2017a) pasa revisión a las formas de aludir a narración, relato e historia, y propone, siguiendo a Norrick (2000), que la historia, la narración y el relato se usan en el sentido habitual en que se generan en la vida cotidiana. Se trata por tanto de un tipo de interacción cara a cara, dinámica, que cambia de orador de manera frecuente. 


\section{LA 'EVALUACIÓN': APROXIMACIONES Y CLASIFICACIONES}

Ya en su publicación de 1972, Labov divide entre aquellos recursos que suspenden la acción, denominados de «evaluación externa», por ejemplo, comentarios realizados por voces externas al relato, como la del narrador y del oyente, y los que preservan la continuidad de la cadena narrativa, que corresponden a los recursos de «evaluación interna». En este último grupo se ubicarían las citas y comentarios de personajes de la historia y también lo que el autor denomina «acciones evaluativas», donde el «hacer» antes que el «decir» es fundamental. Andrews et alii (2013) señalan que, en estricto rigor, Labov (1972) identifica tres tipos principales de evaluación: externa, integrada y evaluativa. La evaluación externa es abierta, es decir, el narrador detiene la acción complicada, se queda fuera de la historia y le dice al oyente cuál es el punto central. La evaluación integrada (o interna), por su parte, conserva la continuidad dramática de la historia mientras los narradores cuentan cómo se sintieron en todo momento. Por último, la acción evaluativa, que se mantiene dentro de la historia al informar acciones que destacan emociones sin emplear el habla (por ejemplo, «me puse a llorar»). Más allá de la taxonomía, lo interesante es que Labov distingue dos grandes medios de que dispone el narrador para evaluar: 1) los que proporcionan unidad lingüística de significado y hacen avanzar la historia, donde se ubicarían todos los verbos «reportables» en el sentido laboviano del término y 2) los que, aun cuando tienen una estructura lingüística, detienen la historia, como las declaraciones de las emociones del narrador. Finalmente, clasifica en cuatro grandes categorías los recursos evaluativos: a) intensificadores, como gestos, recursos fónicos, cuantificadores, repeticiones, entre otros recursos que permiten fortalecer la estructura del relato; b) comparadores, como cláusulas negativas, futuros, preguntas, imperativos y comparativos; c) correlativos, cuya función es unir dos eventos simultáneos en una sola cláusula independiente, por ejemplo, a través del uso de formas verbales progresivas; y, d) explicativos, que explican situaciones que sucedieron antes o después de los eventos narrados, desplazando la atención del oyente a un punto temporal externo al esqueleto de la narración. Se trata, como es evidente, de categorías a las que llega el autor mediante el análisis de narrativas en lengua inglesa, por tanto, no necesariamente se ajustan a la amplia realidad del ámbito hispano.

Jiménez (2006) señala que los seres humanos reaccionan internamente, tienen emociones y motivaciones y las narraciones responden a dichas emociones internas, porque permiten expresar el punto de vista de quien narra. A esta percepción o punto de vista de los hechos es a lo que se le denomina 'evaluación', que, de acuerdo con Labov \& Waletzky (1967), es el elemento clave de una narración. Para Shiro (2003), 
aquellas categorías que hacen referencia a las emociones, intenciones o percepciones reflejan tipos de evaluaciones a través de los cuales se alude a la posición del personaje en el mundo narrado, por lo tanto, constituyen la expresión de un propósito o de una meta. A partir de estos supuestos, Jiménez (2006), basándose en Shiro (2003), analiza siete categorías evaluativas que se describen a continuación: 1) emoción: expresa afecto o emoción, por ejemplo, «se puso contenta» $\left.{ }^{2} ; 2\right)$ cognición: representa el pensamiento y las creencias, por ejemplo, «él pensó que era un pajarito»; 3) percepción: expresa todo lo que se percibe a través de los sentidos, por ejemplo, «vio al policía»; 4) estado físico: se refiere al estado interno más físico que emocional, por ejemplo, «estaba muy cansada»; 5) intención: expresa las intenciones de un personaje al realizar alguna acción, por ejemplo, «trató de escapar»; 6) relación: representa una acción que enfatiza la interpretación de una relación entre personajes o entre un personaje y un objeto, más que la acción en sí misma, por ejemplo, «encontraron al ratoncito»; $y, 7)$ habla reportada: reporta el lenguaje que cita al hablar, por ejemplo, «le dijo: por aquí, señor, por favor» (adaptado de Jiménez 2006: 164-165).

También es relevante la propuesta de Reilly et alii (1990), basada en Labov \& Waletzky (1967) y Labov (1972). Dicha taxonomía diferencia entre recursos de evaluación afectiva, esto es, expresiones de estados emocionales, efectos de sonido o repeticiones, y recursos de cognición social en términos de procesamiento de información social, conocimientos o saberes del narrador acerca de lo narrado y de las relaciones interpersonales. Dentro de los recursos de evaluación afectiva se hallan: 1) estados afectivos, entendidos como aquellos recursos de evaluación que agregan información sobre el mundo interior de los personajes; 2) discurso referido, en tanto recurso dramático que aporta inmediatez y vivacidad a la narración y 3 ) intensificadores, esto es, marcas que contribuyen a crear fuerza o a enfatizar ciertas acciones que el narrador considera importantes. Esta categoría, a su vez, incluye cuantificadores y repeticiones. En relación con los recursos de cognición social, se consideran: 1) estados mentales, cuya labor es ofrecer información acerca de los procesos cognitivos internos de los protagonistas y 2) negaciones, que evalúan por oposición, resaltando aquello que no sucedió. A este respecto, conviene destacar que las investigaciones en ciencia cognitiva, específicamente, aquellas que se interesan por estudiar la teoría de la mente, también proponen clasificaciones de estados mentales, que podemos vincular con el componente evaluativo de la teoría narrativa laboviana. Una taxonomía interesante es la que divide en tres grupos los estados mentales: 1) sentimientos y emociones, 2) percepciones y conocimientos y 3 ) deseos e intenciones. Si bien se trata

Los ejemplos son de Shiro (2003), replicados por Jiménez (2006). 
de un enfoque diferente por situarse en el ámbito cognitivo, se puede apreciar que la división de niveles no dista mucho de las que se han revisado en este apartado, esto como consecuencia de que el marco general, sea en el ámbito del discurso o de la cognición, es el mismo: el de la narración (Bruner 1988, Bocaz 1996, 1998, Symons et alii 2005). En todos los casos, lo relevante es que la 'evaluación' narrativa permite reinterpretar los hechos pasados:

[...] evaluation of the projected events and interactions between the characters (i.e. the possible) is normally conducted through references to past events (i.e. the actual). In other words, in this case, it is the past that is revisited (re-constructed and re-interpreted) in order to be locally movilized as a «guide» for considering what may transpire (Georgakopoulou 2006: 93).

\section{LA 'EVALUACIÓN': CRÍTICAS, REFLEXIONES Y ESBOZO CLASIFICATORIO}

Las críticas que ha recibido la evaluación narrativa no son pocas. Thompson \& Hunston (2001: 5 y ss.) señalan que la evaluación es el término que cubre una amplia gama de expresiones de la actitud o postura del hablante. Es el punto de vista o los sentimientos acerca de las entidades o proposiciones de que se está hablando. Esa actitud puede estar relacionada con la seguridad o la obligación o la conveniencia o cualquiera de una serie de otros conjuntos de valores. Para dichos autores, son tres las principales causas de la importancia de la evaluación: 1) expresa la opinión del hablante y refleja el sistema de valores de la persona y su comunidad, 2) construye y mantiene las relaciones entre el hablante y quien escucha y 3 ) organiza el discurso (esto sucedió y esta es mi opinión sobre eso). La crítica implicada es la escasa relevancia que se le otorga en el modelo laboviano a la relación interpersonal entre los interlocutores.

Cortazzi \& Jin (2001) destacan el hecho de que la evaluación tiene un sentido especializado para referirse a un elemento semántico y/o estructural de la narración. Los autores destacan la importancia del trabajo de Labov \& Waletzky (1967) y ponen de relieve que la evaluación se considera clave en la narración, porque a través de ella los hablantes muestran cómo debe entenderse el relato y cuál es su punto central. La evaluación muestra emociones o actitudes frente a lo narrado; sin embargo, insisten en que el modelo de Labov deja fuera la relación entre el hablante y el oyente. Para dichos investigadores existirían tres formas de evaluación: 1) la evaluación en la narración, esto es, la relación de la evaluación en narraciones de experiencia personal con la 
función social del relato. Se plantea que los elementos evaluativos se dan semánticamente, gramaticalmente o a nivel de prosodia; 2) la evaluación de la narración, donde se expresa la crítica al modelo laboviano, que considera la evaluación como parte de la estructura secundaria. Citando a Hymes (1981), Cortazzi \& Jin (2001) demuestran que la evaluación no es solo parte de la estructura secundaria, ya que está presente en recursos paralelos a la estructura principal y en segmentos de término del relato, incluyendo gestos, efectos vocales, diferentes tonos de voz, entre otros aspectos. Los autores señalan que lo que habría que determinar es qué pertenece a la narrativa y qué a la evaluación y 3) la evaluación a través de la narración, donde queda de manifiesto cómo los narradores, los oyentes o sus situaciones son evaluados a través del habla. Finalmente, el trabajo destaca que, a veces, la evaluación en, de y a través de la narración es una autoevaluación, es decir, los hablantes pueden evaluar su sentido del yo individual y colectivo, pues en las narraciones de experiencia personal recordamos como fuimos, como somos y como deseamos ser. Se trata de tener conciencia de varios puntos de vista.

En lo que respecta a las reflexiones en torno a las propuestas descritas, en esta nota se sugiere que, si bien la propuesta original de Labov (1972) es completa, su foco está centrado en la sintaxis narrativa, por ejemplo, si se trata de cláusulas subordinadas o independientes. Dicha propuesta no es por tanto la más idónea cuando lo que se busca estudiar es la disponibilidad de recursos lingüísticos de evaluación de los que dispone el narrador para construir su historia y hacerla «reportable». En otras palabras, se propone estudiar la sintaxis narrativa en conjunto con los recursos de evaluación empleados por el narrador. Con esto no se niega la relevancia de llevar a cabo investigaciones cuyo énfasis sea más bien la construcción de eventos, pero se cree que una forma de dar cuenta de cómo se transmite el sentido de una historia es mediante la manifestación de motivos, reacciones de los personajes y del narrador, lo que es más evidente en las propuestas de Reilly et alii (1990) y Shiro (2003).

Respecto de Shiro (2003) — cuya taxonomía replica Jiménez (2006) — se considera que si bien su propuesta de recursos evaluativos es apropiada, habría que hacer aclaraciones al respecto, puesto que incluye algunos ejemplos poco acertados, lo que podría inducir a errores en el análisis de otros investigadores. Es lo que ocurre, por ejemplo, con las relaciones, cuyo ejemplo («encontraron al ratoncito») no ilustra el contenido definido. La categoría aludida resulta muy subjetiva en un análisis, porque queda a juicio del investigador dónde está puesto el énfasis, esto es, o en la acción misma o en la relación que se establece en dicha acción. También sería interesante reclasificar las categorías de Shiro (2003) basándose en las de Reilly et alii (1990), quienes —a su vez - utilizan algunas de Labov (1972). Esto ayudaría, por ejemplo, 
a hacer más transparentes las definiciones, puesto que se trata de una propuesta más general: evaluación afectiva y recursos de cognición social. Entre los recursos de evaluación afectiva se hallarían principalmente las emociones y entre los de cognición social se ubicarían los verbos de estados mentales, las percepciones y las intenciones.

Como consecuencia de las revisiones teóricas y de las reflexiones expuestas, se presenta el esbozo clasificatorio de recursos lingüísticos de evaluación en la narración. Esta propuesta está basada, primero, en el trabajo de Labov \& Waletzky (1972) y, en segundo orden, en el estudio empírico de 108 narraciones de experiencia personal pertenecientes al corpus del Proyecto para el Estudio Sociolingüístico del Español de España y América (PRESEEA) de Santiago de Chile y 54 narraciones conversacionales videograbadas de hablantes de español chileno. Todos los ejemplos citados de aquí en adelante corresponden a dichos materiales.

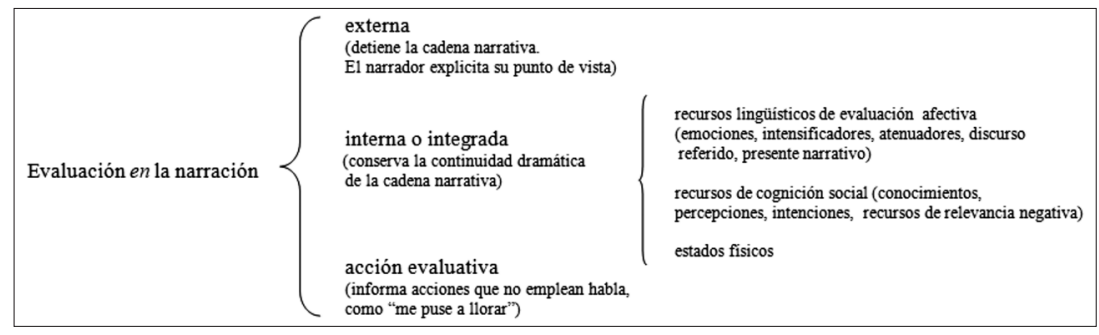

ESQUEMA 1. Evaluación en la narración

El esbozo propuesto divide entre evaluación externa, que en estricto rigor es la que detiene la cadena narrativa, como ocurre, por ejemplo, cuando quien narra detiene la historia y hace comentarios que expliquen cierto aspecto de lo que se está contando; la interna, entendida como aquella que preserva la cadena del relato; y la acción evaluativa, donde importa más lo que el narrador «hace» en términos ilocutivos que lo que «dice».

Es la evaluación interna o integrada la que incluye la mayor gama de expresiones de la actitud o postura del hablante. Consiguientemente, se puede dividir entre recursos de evaluación afectiva, que implican estados emocionales o del mundo interior de los narradores y que dotan de mayor dramatismo la historia; recursos de cognición social o expresiones que representan estados mentales de los hablantes; y estados físicos, que no pueden incluirse en los casos anteriores. Los casos específicos se definen a continuación. 
i. Recursos de evaluación afectiva ${ }^{3}$ :

a. Emociones o estados afectivos: recursos lingüísticos que portan información sobre el mundo interior de los personajes e involucran una alteración del ánimo, ayudando a desarrollar la personalidad de los mismos, por ejemplo, «me dio mucha vergüenza»o «estaba muy feliz».

b. Intensificadores: marcas lingüísticas que contribuyen a crear fuerza o a enfatizar ciertas acciones que el narrador considera importantes, por ejemplo, «como algo muy chistoso». En el ejemplo, solo la palabra «muy» es un intensificador. En esta categoría se incluyen también las repeticiones.

c. Atenuadores: recursos lingüísticos cuya función es mitigar o minimizar la intensidad de lo expresado y reducir lo que se calcula por los hablantes como amenazante o como menos exitoso en un determinado contexto (Albelda 2010), por ejemplo, «[yo] sentí que estaba como cansado de la relación», donde «como» mitiga o atenúa el compromiso del hablante con lo que cuenta. Se trata de un recurso de evaluación afectiva toda vez que verbo «sentir»—que es aquel con el que el hablante muestra su propio punto de vista: «[yo] sentí»— deja abierta la opción de incluir otros puntos de vistas posibles, ya que al combinarse con «como» expresa duda o incertidumbre por parte del hablante, y que podría reflejar, por tanto, su mundo interno. Los atenuadores aparecen muy vinculados a la orientación narrativa, que también puede ser evaluada, como han demostrado González \& Guerrero (2018).

d. Discurso referido: recurso lingüístico que permite a los hablantes recrear una situación discursiva, lo que se materializa en la reproducción de los enunciados proferidos por las voces intervinientes (San Martín \& Guerrero 2013: 260). Puede ser visto como un elemento dinámico y de dramatismo en la narración, por lo que se

Entre los recursos que se mencionan a continuación se hallan los ‘intensificadores' y 'atenuadores'. Estamos conscientes de que se trata de recursos evaluativos que podrían estudiarse y, de hecho, han sido estudiados desde el sistema de Gradación en el marco de la Teoría de la Valoración (Martin \& White 2005), como ocurre en González y Guerrero (2016). Lo mismo podría argumentarse respecto del 'discurso referido'. Sin embargo, aquí se incluyen dentro de la categoría de evaluación afectiva, puesto que reflejan en gran medida el mundo interno de los narradores. Esto no es incompatible con la propuesta que señala que se trata de recursos que permiten graduar lo relatado, sino que constituye solo una forma de organización de la evaluación en el contexto de la amplia propuesta de William Labov. Debe precisarse que los 'atenuadores', en tanto recurso evaluativo, deben tratarse con cautela, dado que no funcionan como partículas aisladas, sino que se combinan con otros atenuantes que, en su conjunto, permiten configurar la evaluación. Además, podría argüirse que hay casos donde se trata más bien de recursos evaluativos de cognición social. Es lo que podría ocurrir, por ejemplo, con el verbo mental «creer» en «creo que era jueves cuando sucedió». Lo que se sugiere es que el analista mire este tipo de recursos sabiendo que se articulan de manera solidaria con otros atenuantes y que siempre se relacionan con la comunicación no verbal. 
considera de evaluación afectiva. Camargo (2004) postula que las citas manifiestan la percepción del mundo interior del hablante y son una muestra de que la lengua es vital para dar cuenta de su punto de vista sobre los acontecimientos narrados y sobre el universo en que dichas acciones ocurren. Para San Martín \& Guerrero (2013), existen cinco variantes específicas de discurso referido: a) discurso directo libre, donde no hay ningún elemento introductor de la cita: «y, y, ya entrega todo»; b) discurso directo con pronombre personal: «ya, yo: ya bacán»; c) discurso directo convencional: «y había un curado abajo que decía: oye, apúrate. Sube po luego, para que nos saquemos las botellas»; d) discurso indirecto convencional: «me dijo que yo no había tenido la culpa»; y, e) discurso indirecto narrativizado: «y me puse a hablarles y a darles consejos y a hablarles de la vida y del futuro y del valor del ser humano y todo eso».

e. Presente narrativo ${ }^{4}$ : corresponde a un uso particular de las formas de presente para hacer referencia a situaciones pasadas (miro por miré). Alarcos Llorach (1994: 156) señala que «se llama presente histórico al empleo, tanto en la narración escrita como en el vivo relato coloquial, de las formas de presente para aludir a hechos cronológicamente ocurridos en el pasado». Los estudios sobre presente histórico concuerdan en que este uso particular del presente indicativo tiene efectos estilísticos en el discurso, dotándolo de mayor fuerza, viveza y dramatismo. La Nueva Gramática de la Lengua Española (RAE, 2010) incorpora la diferencia entre «presente histórico», característico de las biografías y de las descripciones históricas, y «presente narrativo», propio de las narraciones y compatible con los eventos referidos en pasado. Ambos casos consisten en valores trasladados del verbo - uso del presente morfológico para referir al pasado - cuya diferencia está dada por el propósito comunicativo y por el contexto de aparición (Guerrero \& Arriagada 2017).

ii. Recursos de cognición social

a. Construcciones con verbos de estados mentales o conocimiento: construcciones discursivas que se introducen a través de verbos que representan pensamientos, creencias o conocimientos de los personajes: saber, querer, desear, pensar, suponer, creer, por ejemplo, «yo en mi sueño pensé que era la otra señora».

b. Percepciones: sensaciones o imágenes interiores que resultan de una impresión material hecha por nuestros sentidos, sea de personas, situaciones u objetos, siempre que se trate de características o hechos subjetivos, por ejemplo, «y mi amiga, ya, ultra cara de vergüenza».

$4 \quad$ No aparece en las propuestas descritas anteriormente. Para revisiones más detalladas, ver Guerrero (2014), Guerrero \& Arriagada (2017) y Lastra \& Butragueño (2017). 
c. Intenciones: expresan las intenciones, las motivaciones o las metas de un personaje al realizar alguna acción. Al momento de la enunciación, implican probabilidad, por ejemplo, «yo quería ir a visitarla», donde -ría representa un valor modal potencial de una acción que solo sabremos si se concretó al avanzar el relato.

d. Recursos de relevancia negativa: evalúan por oposición, resaltando aquello que no sucedió o destacando la ausencia de características, creencias, personas o bienes materiales, entre otros elementos que ayudan a dar cuenta de la relevancia de la historia, por ejemplo, «pero no se fueron con los celulares».

iii. Estados físicos: se refieren a los estados internos de los personajes, más físicos que emocionales, por ejemplo, «estábamos muertos de hambre».

Esta taxonomía constituye solo una propuesta sobre cómo aproximarse a los estudios de la 'evaluación' narrativa. Se trata de un intento de ordenar las variadas propuestas existentes y, en ningún caso, implica que no haya otros recursos de evaluación en la narración o que las definiciones no puedan mejorarse. En este caso, se han incluido recursos lingüísticos que han demostrado ser altamente empleados y variables en cuanto a su uso en diversas comunidades de habla. No obstante, debe insistirse en que constituyen solo un esbozo clasificatorio de los recursos que utiliza el narrador para mostrar su punto de vista y/o para hacer de su historia una narrativa más dinámica y, por ende, «reportable».

En investigaciones de autoría propia aparecen casos como los que se citan a continuación, derivados de los corpus citados más arriba.

(1) bueno/ finalmente en la posta le sacan el poroto [bueno]/ y después era contárselo a la mamá/ bueno la mama no estaba muy/ [muy contenta] muy contenta [sí] pero en el fondo tampoco ella se había dado cuenta porque el niño estaba con el poroto desde el día anterior (corpus narraciones conversacionales).

(2) se había calentado el auto y se había roto el buje que llevaba la hélice del motor// entonces había que volver a buscarla [...] y yo pensaba entre mí qué vamos a hacer ahora/ la cantidad de cuestiones que van atrás (corpus narraciones conversacionales).

(3) sí y después la moto / la moto quedó en la casa / y casi nadie creía como habíamos / pensaban que nosotros nos habíamos matado también (corpus PRESEEA-Santiago de Chile).

(1) y (2) referidos en Guerrero (2019) dan cuenta de la incorporación de varios recursos con los que los narradores van evaluando la historia. En (1) se observa el 
empleo del presente narrativo «sacan» y la valoración respecto del estado emocional de la madre, que incluye intensificadores y repeticiones: «no estaba muy/ [muy contenta] muy contenta». La narradora agrega atenuantes «bueno»y «en el fondo» para proteger la imagen propia delegando la responsabilidad del incidente en otra persona. En (2) se observa el uso de un verbo de estado mental que permite valorar lo que el narrador creía o pensaba al momento de suceder los hechos relatados. El ejemplo (3) comienza evaluando el accidente narrado desde la perspectiva del otro, asignándole estados mentales y atenuando con el uso de aproximativos o difusores del significado «casi», nuevamente para autoproteger la imagen propia al valorar el discurso (Guerrero, en prensa).

Como se ha demostrado con los ejemplos, el factor que hasta ahora parece quedar fuera de estos estudios es la comunicación no verbal, en tanto sistema en el cual están implicados todos los elementos culturales y los signos no verbales de los que disponen los hablantes en el proceso comunicativo (Cestero 2004, 2009, 2014).

\section{LA 'EVALUACIÓN': EL ROL DE LA COMUNICACIÓN NO VERBAL}

Como es bien sabido, los sistemas de comunicación son tres: lingüísticos, paralingüísticos y quinésicos ${ }^{5}$. La comunicación no verbal queda conformada por los dos últimos. Cestero (2009 y 2016a) precisa que dentro del sistema paralingüístico se ubican las cualidades físicas del sonido (tono, intensidad $u$ otras), las reacciones fisiológicas (risa, llanto, suspiros, entre otras), los elementos cuasi-léxicos (como las consonantizaciones) y la ausencia de sonido. En el sistema quinésico se encuentran los gestos faciales y corporales, las maneras (movimientos, toma de posiciones, etc.) y las posturas (o posiciones estáticas). Se agregan a estos los sistemas de comunicación no verbal culturales: la proxémica y la cronémica. En lo que se refiere a las características de la comunicación no verbal, Cestero (2016a) incluye que: 1) comunica activa o pasivamente, 2) es funcional, 3) es plurifuncional, 4) es susceptible de variación, 5) se puede combinar con la comunicación verbal y 6) comunica y regula el mensaje.

Ekman \& Friesen (1969) señalan que los actos no verbales se clasifican en cinco tipos genéricos: emblemas, ilustradores, reguladores, adaptadores y expresiones o manifestaciones de afecto o emoción. Alvarez (2003), en tanto, precisa que Ekman (1973) se referirá, dentro de los movimientos faciales, a los emblemas, ilustradores y reguladores como 'conversational signals' (o 'señales de conversación') para distinguirlos de las expresiones de emoción.

Para la estructura triple básica del discurso, ver Poyatos (2017). 
Según los presupuestos anteriores y de acuerdo con los hallazgos de Guerrero (2017b), en esta nota se sostiene que a nivel de paralenguaje, por lo menos, el tono (subida o bajada tonal), la velocidad del habla, los alargamientos, las risas, los suspiros y las pausas y silencios permiten evaluar aquello que se está contando. Por ejemplo, si un narrador ríe o habla entre risas a la vez que cuenta una parte de su historia, está claramente mostrando emoción frente a lo narrado. Asimismo, si sube o baja el tono, o alarga segmentos discursivos, está intentando llamar la atención del interlocutor frente a lo narrado. Según los postulados de Cortazi \& Jin (2011), la prosodia, el tono y los gestos permiten evaluar dentro de la cadena narrativa. De este modo, queda cubierto en mayor grado lo que Thompson \& Hunston (2001) precisan respecto de que la evaluación no solo expresa la opinión del hablante, sino que además construye y mantiene las relaciones entre el hablante o escritor y quien escucha. Sería, en buena parte, el paralenguaje el que pondría de manifiesto la relación interpersonal entre los interlocutores. También Labov (1972) alude a los recursos fónicos como parte de aquellos recursos que permiten evaluar en la narración. Así ocurre, por ejemplo, con el tono para intensificar o atenuar.

En relación con los gestos, en lo que se refiere a la expresión facial, la mirada es fundamental para evaluar lo que se está contando, sea dirigida al interlocutor o hacia el horizonte, pues, en el primer caso, da cuenta de la inclusión del interlocutor en la historia y, en el segundo, del grado de involucramiento del propio narrador con su relato. Se incluye también como caso recurrente de recurso no verbal de evaluación la gran abertura de ojos. A nivel de expresión corporal, podrían incluirse los gestos manuales, como las manotadas o los giros manuales, en tanto formas de evaluar y de manifestar afecto y/o emoción.

Por último, se sugiere que incluso el comportamiento proxémico del tipo inclinación hacia adelante o inclinación hacia atrás podría marcar ciertas formas de evaluar en la narración, en especial, si están acompañados de elementos paraverbales, como la subida o la bajada del tono.

Resultados más precisos del comportamiento no verbal de todos los recursos descritos se hallan en Guerrero (2017b). Solo para ilustrar se incluye la Imagen 1, del corpus de narraciones conversacionales en español chileno, donde puede verse el gesto manual de la narradora, cuyo propósito es manifestar emoción al intensificar aquello que relata. Con dicha intensificación genera una mayor teatralidad de la escena, que verbalmente incluye el presente narrativo «me pongo a llorar». 


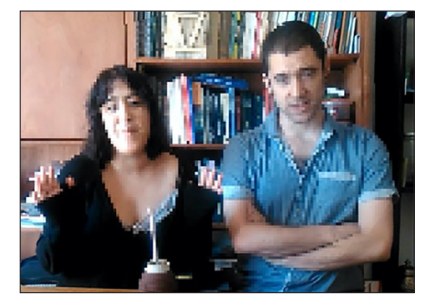

IMAGEN 1. Gesto manual en narración conversacional

Transcripción:

A: eso/ le dije: «usted me está retando más que contenerme y eso no está en la ética profesional»// no/ así/ me pongo a llorar ¡Paf! [Acompaña con la sacudida de ambas manos para intensificar lo que señala].

Para el estudio de la evaluación narrativa será esencial disponer de material audiovisual, dada la cantidad de gestos implicados en el discurso. Si en un mismo momento del discurso se presenta, por ejemplo, un aumento de la velocidad del habla, cuyo propósito es enfatizar lo que se dice, sumado a una gran abertura de ojos, para llamar la atención del interlocutor frente a lo narrado o para demostrar la emoción del propio narrador, solo podrá registrarse esa información a través de videograbaciones. La comunicación no verbal, en este sentido, puede entenderse como una forma de interacción que en principio es susceptible de ser controlada por los hablantes, aunque en la práctica esté menos conscientemente controlada o sea menos controlable, como tantas estrategias discursivas (Wodak \& Meyer 2003). Por ello, un análisis acabado de la evaluación narrativa requiere necesariamente la inclusión del estudio de la comunicación no verbal, puesto que se trata de signos resaltadores de información relevante. Si bien Labov (1972) incluye los gestos dentro de los intensificadores, parece ser que lo hace desde un plano secundario donde prima aquello que se dice.

En una dimensión diferente, basada en el discurso persuasivo, Cestero (2018) señala que la comunicación no verbal facilita el entendimiento del mensaje, pues expresa actitudes, emociones y estados psicológicos. Entre sus hallazgos destaca el rol de la sonrisa y la mirada, que permiten al hablante posicionarse; son también relevantes la elevación de las cejas y el parpadeo, que permiten resaltar información relevante; y resultan fundamentales, a la vez, las manotadas y los giros manuales, que se emplean también para resaltar información. El valor que le asigna la autora a este tipo de gestos en el ámbito del discurso persuasivo es similar al que ha destacado Guerrero (2017b) para el desarrollo de la narrativa oral. Se trata de hallazgos similares en la medida en 
que funcionan como marcas de comunicación no verbal que permiten, sin importar el tipo de secuencia discursiva, destacar o resaltar aquello que se quiere decir.

El primer esquema presentado en esta nota queda actualizado a partir de la inclusión de la comunicación no verbal dentro de los recursos de evaluación afectiva, según los hallazgos de Guerrero $(2017 b)^{6}$, como sigue:

Evaluación de la narración $\longrightarrow \begin{gathered}\text { interna o integrada } \\ \text { (conserva la continuidad } \\ \text { dramática de la cadena narrativa) }\end{gathered} \quad \begin{aligned} & \text { recursos no verbales de evaluación afectiva } \\ & \text { (emociones, intensificadores, atenuadores) }\end{aligned}$

ESQUEMA 2. Evaluación de la narración

i. Recursos de evaluación afectiva:

a. Emociones o estados afectivos: se agregan a los recursos de evaluación lingüística, a nivel de paralenguaje, las reacciones psicológicas que aluden a risas o segmentos discursivos proferidos entre risas. Además, quedan incluidas, a nivel de quinésica referida a la expresión facial, las sonrisas y las miradas. Se trata, en todos los casos, de recursos de comunicación no verbal que contribuyen a describir el mundo interior y las emociones de los narradores.

b. Intensificadores: se incluyen a nivel de paralenguaje los elementos fónicos como el tono, la velocidad del habla y los alargamientos; a nivel de quinésica referida a la expresión facial, marcadores faciales como la gran abertura de ojos, el parpadeo y la elevación de las cejas; a nivel de quinésica en relación con la expresión corporal, los gestos manuales del tipo manotadas y giros; $y$, en cuanto a la proxémica, la inclinación hacia adelante o hacia atrás.

c. Atenuadores: a nivel de paralenguaje, funcionan como atenuadores los elementos fónicos como el tono, la velocidad del habla, los alargamientos, las risas y las pausas y silencios; a nivel de quinésica de la expresión facial, marcadores faciales como el parpadeo y el arrugamiento del ceño; a nivel de quinésica de la expresión corporal, los gestos manuales que refuercen la emoción de lo dicho; $\mathrm{y}$, en la proxémica también pueden incluirse la inclinación hacia adelante o hacia atrás.

Todos estos recursos complementan a aquellos descritos para la comunicación verbal y se sugiere que se estudien por tanto de manera integrada, puesto que aportan a expresar emoción, crear fuerza o a mitigar aquello que se narra.

Estos hallazgos corresponden a la aplicación en secuencias narrativas de la variedad chilena del español de la clasificación de recursos de comunicación no verbal de Cestero (2016a). 


\section{REFLEXIONES FINALES Y PROYECCIONES}

En esta nota se ha desarrollado una reflexión acerca del tratamiento que ha recibido la 'evaluación' narrativa (Labov 1972, 2013) en investigaciones con enfoques bien diferentes, cuya revisión permitió proponer el esbozo clasificatorio - claramente tentativo - de recursos de evaluación lingüística. A esta taxonomía se agregan aspectos de la comunicación no verbal que también funcionan como recursos de evaluación dentro del relato oral. Si bien no se hizo una propuesta detallada a este respecto, se revisaron los elementos del paralenguaje y los gestos que, hasta ahora, han mostrado desempeñar un rol cardinal dentro de la valoración de la narración y que, por supuesto, vienen a completar el sistema lingüístico.

Un trabajo pionero en este tema es el que realiza Maulén (2018), quien desarrolla una propuesta de estilos narrativos — basándose en Hernández-Campoy (2016) — en el relato conversacional; uno de dichos estilos es el 'colaborativo', caracterizado por la cesión reiterada de turnos mediante el empleo de recursos verbales - como los marcadores de control de contacto- y no verbales — como las miradas, la comunicación proxémica y la quinésica- El autor destaca el valor de la sonrisa, cuya función pragmática, al igual que el de las miradas, es incuestionable, dado que es uno de los aspectos más notorios en situaciones interaccionales, ya que transmite una gran cantidad de información pragmática referida a la intencionalidad y al estado de ánimo del hablante, lo que constituye un factor determinante en las interacciones cara-a-cara y cuenta con el poder de influir, modificar y crear contextos, vale decir, evalúa lo dicho.

Tomando como base los aportes realizados en esta nota, así como los de Cestero (2016a, 2016b, 2018), Guerrero (2017b), Maulén (2018) y otros investigadores citados en las páginas previas, se sostiene que la evaluación narrativa debe estudiarse idealmente en el contexto de la narración que se genera en la conversación cotidiana, donde pueda evaluarse el éxito de la transmisión de significado a partir del uso de expresiones lingüísticas y recursos de comunicación no verbal que manifiesten la relevancia que los hechos tienen para el narrador en términos emocionales y sociales. En este sentido, la evaluación debe entenderse y estudiarse como un recurso complejo -que implica las dimensiones fonética, sintáctica, discursiva y no verbal—, que siempre estará presente en los relatos, con el propósito de dar cuenta de la actitud o de la postura de quien narra frente a los sucesos relatados. Si no hubiera evaluación, se trataría de una simple secuencia de eventos (y no de una narración), según De Fina y Georgakopoulou (2012). En una narración, quien relata es capaz de (re)interpretar los hechos y valorar sus principales características, sea de manera explícita, a través del uso de ciertos recursos lingüísticos, o complementando con signos propios de la comunicación no verbal, como se ha expresado en esta nota. 
Futuros trabajos en esta línea permitirán realizar un análisis más detallado, empleando, por ejemplo, otros marcos teóricos, como el Modelo de la Valoración desarrollado por Jim Martin y Peter White (Martin \& White 2005), para seguir completando la propuesta de recursos de evaluación. En lo que respecta al valor de los gestos y del paralenguaje dentro de la narrativa oral, los trabajos son más bien incipientes y el desafío es realizar propuestas más detalladas basadas en trabajo de corpus.

\section{BIBLIOGRAFÍA}

Alarcos Llorach, E. (1994): Gramática de la lengua española. Madrid: Espasa Calpe.

Albelda, M. (2010): «¿Cómo se reconoce la atenuación? Una aproximación metodológica basada en el español peninsular hablado», (Des)cortesía en español. Espacios teóricos y metodológicos para su estudio, pp. 41-70.

Álvarez de ArCAYA AJuria, H. (2003): «La comunicación no verbal. Interrelaciones entre las expresiones faciales innatas y las aprendidas», Gazeta de Antropología 19, pp. 1-10. http://www.gazeta-antropologia.es/ [última consulta: 16/03/2020].

Andrews, M. \& C. SQuire \& M. TAMBoukou (2013): Doing narrative research. LA: Sage Publications Ltd.

Bocaz, A. (1996): «El paisaje de la conciencia en la producción de narraciones infantiles», Lenguas Modernas 23, pp. 49-68.

BocAz, A. (1998): «La construcción del paisaje de la conciencia por niños de diferentes estratos socioeconómicos», Lenguas Modernas 25, pp. 71-94.

BRUner, J. (1988): Desarrollo cognitivo y educación. Madrid: Morata.

CAMARgo Fernández, L. (2004): La Representación del Discurso en la Narración Oral Conversacional. Estudio Sociopragmático. Tesis doctoral. Madrid: Universidad de Alcalá.

Cestero, A. M. (2004): «La comunicación no verbal y el aprendizaje de lenguas extranjeras», in J. Sánchez Lobato \& I. Santos Gargallo (dirs.): Vademécum para la formación de profesores. Enseñar español como segunda lengua/lengua extranjera. Madrid: SGEL, pp. 593-616.

Cestero, A. M. (2009): «Marcas paralingüísticas y quinésicas de la ironía», in L. Ruiz Gurillo \& X. A. Padilla García (eds.): Dime cómo ironizas y te diré quién eres. Una aproximación pragmática a la ironía. Frankfurt am Main: Peter Lang, pp. 167-190. 
Cestero, A. M. (2014): «Comunicación no verbal y comunicación eficaz», ELUA Estudios de Lingüistica 28, pp. 125-150. http://dx.doi.org/10.14198/ ELUA2014.28.05

Cestero, A. M. (2016a): «La Comunicación no verbal: propuestas metodológicas para su estudio», Lingüistica en la Red. Disponible en: http://www.linred.es/ [última consulta: 28/01/2019].

Cestero, A. M. (2016b): «La atenuación en el habla de Madrid: patrones sociopragmáticos», RILCE33,1, pp. 57-86.https://doi.org/10.15581/008.33.1.57-86

Cestero, A. M. (2018): «Recursos no verbales en comunicación persuasiva: gestos», Zer 23,44, pp. 69-92. https://doi.org/10.1387/zer. 18130

CORTAZZI, M. \& L. JIN (2001): «Evaluating evaluation in narrative», in S. Hunston \& G.Thompson (eds.): Evaluation in Text. Oxford: Oxford University Press, pp. 384-394.

De Fina, A. \& A. Georgakopoulou (2012): Analyzing narrative. Discourse and sociolinguistic perspectives. Cambridge: University Press. https://doi.org/10.1017/ S0047404513000997

EkMAN, P. (1973): «Cross cultural studies of facial expression», in P. Ekman (ed.): Darwin and facial expression. New York, Academic Press, pp. 169-222.

EkMAN, P. \& D. Friesen (1969): «The repertoire of non-verbal behaviour: categories, origins, usage and coding», Semiotica 1, pp. 49-98. https://doi. org/10.1515/9783110880021.57

Georgakopoulou, A. (2006): «Small and large identities in narrative (inter)action», in A. De Fina \& D. Schiffrin \& M. Bamberg (eds.): Discourse and identity. Cambridge: Cambridge University Press, pp. 121-143.

GonzÁlez, J. \& S. Guerrero (2016): «Estudio sociolingüístico del empleo de gradación de valoraciones inscritas en discursos argumentativos en el corpus PRESEEA de Santiago de Chile», Linred 14. Disponible en: http://www.linred. es/articulos_pdf/LR-articulo-10102016.pdf [última consulta: 28/01/2019].

GonzÁlez, J. \& S. Guerrero (2018): «Recursos de atenuación en la 'orientación' de narrativas personales orales desde una perspectiva sociopragmática», Nueva revista del Pacifico 68, pp. 62-81. http://dx.doi.org/10.4067/S0719-51762018000100062

GUERRERO, S. (2014): Variación discursiva en narraciones de experiencia personal en el español hablado en Santiago de Chile. Tesis doctoral. Santiago de Chile: Pontificia Universidad Católica de Chile. 
GuERRERO, S. (2017a): «Los reguladores no verbales de inicio de secuencia estructural en narraciones conversacionales: un estudio sociopragmático», Pragmalingüistica 25, pp. 267-285. https://revistas.uca.es/index.php/pragma/article/view/3311

GUERRERO, S. (2017b): «Narración individual versus narración conversacional: un puente entre el variacionismo y la interacción», Onomázein 38, pp. 58-87. DOI: 10.7764/onomazein.38.04.

GUERRERO, S. (2019): «Narración individual versus narración conversacional: análisis de las diferencias de superficie», Cuadernos de Lingüistica de El Colegio de México 6,1, pp. 1-42. http://dx.doi.org/10.24201/clecm.v6i1.93

Guerrero, S. (En prensa): «La atenuación lingüística en el corpus PRESEEA de Santiago de Chile», Revista Alpha.

GUERRERO, S. \& S. Arriagada (2017): Guía de estudios del presente narrativo en los corpus PRESEEA. http://preseea,linguas,net/Metodolog\%C3\%ADa, aspx [última consulta: $16 / 03 / 2020]$.

Hernández-CAmpoy, J. M. (2016): Sociolinguistic Styles. UK: John Wiley \& Sons, Inc. HyMES, D. (1981): In Vain I Tried to tell you: Essays in Native American Ethnopoetics. Philadelphia: University of Pennsylvania Press.

JIMÉNEZ, T. (2006): «La narración infantil. Un estudio en niños de educación básica», Revista de investigación 60, pp. 157-174. https://dialnet.unirioja.es/servlet/ articulo? codigo $=2324945$

LABOV, W. (1972): «The transformation of experience in narrative syntax», in Language in the inner city. Studies in the Black English Vernacular. Filadelfia: University of Pennsylvania Press, pp. 395-415.

Labov, W. (2013): The language of life and death. The transformation of experience in oral narrative. Cambridge: University Press.

LABOv, W. \& J. WALETZKY (1967): «Narrative analysis», in J. Helm: Essays on the verbal and visual arts. Seattle: University of Washington Press, pp. 12-44.

Lastra, Y. \& P. M. Butragueño (2017): «El presente narrativo en historias de experiencia personal en el Corpus sociolingüístico de la Ciudad de México». Ponencia XVIII Congreso Internacional de ALFAL, 24-28 julio de 2017. Bogotá: Colombia.

Martin, J. \& P. White (2005): The Language of Evaluation. Appraisal in English. New York: Palgrave Macmillan.

MAULÉN, G. (2018): Estilos narrativos en relatos conversacionales de hablantes de Santiago de Chile. Tesis de Licenciatura. Chile: Universidad de Chile. 
NorRICK, N. (2000): Conversational narrative. Saarland University: John Benjamins Publishing Company.

Poyatos, F. (2017): «La comunicación no verbal en la enseñanza integral del Español como Lengua Extranjera», E-eleando ELE en RED. Alcalá de Henares: Universidad de Alcalá.

Real Academia Española y Asociación de Academias de la Lengua Española (2010): Nueva gramática de la lengua española. Manual. Madrid: Espasa.

Reilly, J. \& K. Edwards \& U. Bellugi (1990): «One more with feeling: affect and language in atypical populations», Development and Psychopathology 2, pp. 367-391. https://doi.org/10.1017/S0954579400005782

SAN MARTín, A. \& S. GuerRero (2013): «Una aproximación sociolingüística al empleo del discurso referido en el corpus PRESEEA de Santiago de Chile», Revista Signos 46,82, pp. 258-282. http://dx.doi.org/10.4067/S0718-09342013000200005

SHIRO, M. (2003): «Genre and Evaluation in Narrative Development», Journal of Child Language 30, pp. 165-195. https://doi.org/10.1017/S0305000902005500

Silva-Corvalán, C. \& A. Enrique-Arias (2017): Sociolingüistica y pragmática del español. Washington: Georgetown University Press [2 ${ }^{\mathrm{a}}$ edición].

Symons, D. \& C. Peterson \& V. Slaughter \& J. Roche \& E. Doyle (2005): «Theory of mind and mental state discourse during book reading and story-telling tasks», British Journal of Developmental Psychology 23, pp. 81-102. https://doi. org/10.1348/026151004X21080

Thompson, G. \& S. Hunston (2001): Evaluation in Text. Oxford: Oxford University Press.

WodAK, R. \& M. Meyer (2003): Métodos de análisis crítico del discurso. Barcelona: Gedisa. 